\title{
Cognitive function in a general population of men and women: a cross sectional study in the European Investigation of Cancer-Norfolk cohort (EPIC-Norfolk)
}

\author{
Shabina A Hayat ${ }^{1 *}$, Robert Luben ${ }^{1}$, Stephanie Moore ${ }^{1}$, Nichola Dalzell ${ }^{1}$, Amit Bhaniani', Serena Anuj ${ }^{1}$, \\ Fiona E Matthews ${ }^{2}$, Nick Wareham ${ }^{3}$, Kay-Tee Khaw ${ }^{1}$ and Carol Brayne ${ }^{1}$
}

\begin{abstract}
Background: Although ageing is strongly associated with cognitive decline, a wide range of cognitive ability is observed in older populations with varying rates of change across different cognitive domains.

Methods: Cognitive function was measured as part of the third health examination of the European Prospective Investigation of Cancer in Norfolk (EPIC-Norfolk 3) between 2006 and 2011 (including measures from the pilot phase from 2004 to 2006). This was done using a battery consisting of seven previously validated cognitive function tests assessing both global function and specific domains. The battery included a shortened version of the Extended Mental State Exam (SF-EMSE); letter cancellation task; Hopkins Verbal Learning Test (HVLT); Cambridge Neuropsychological Test Automated Battery Paired Associates Learning Test (CANTAB-PAL); Visual Sensitivity Test (VST); Shortened version of the National Adult Reading Test (Short-NART) and a task to test for prospective memory. We report the distribution of cognitive function in different cognitive domains by age and sex and compare the utility of a number of assessment tests in a general population of older men and women.

Results: Cognitive test data were available for 8585 men and women taking part in EPIC-Norfolk 3. Increasing age was generally associated with declining mean cognitive function, but there was a wide range observed within each age group as well as variability across different cognitive domains. Some sex differences were also observed.
\end{abstract}

Conclusion: Descriptive data are presented for this general population sample of older men and women. There is a wide range of cognitive performance seen in this population. Though average performance declines with age, there is large individual variability across different cognitive domains. These variations may provide insights into the determinants of cognitive function in later life.

Keywords: Ag(e)ing, Follow up studies, United Kingdom, Middle aged, Cognition, Cognition disorders

\section{Background}

Ageing is generally associated with memory impairment and cognitive decline, however, this decline is not inevitable [1] and not all domains of cognitive function are equally affected with age [2]. A broad range of cognitive capability is observed in the older population [3] as well as substantial inter-individual heterogeneity in rates of

\footnotetext{
* Correspondence: Shabina.hayat@phpc.cam.ac.uk

'Department of Public Health and Primary Care, Institute of Public Health, University of Cambridge School of Clinical Medicine, Cambridge, UK Full list of author information is available at the end of the article
}

decline [4]. The range encompasses high cognitive functioning even in the very old [5], mild cognitive impairment (MCI), through to dementia at the other end of the spectrum.

Mild Cognitive Impairment (MCI) is described as the transitional state between normal cognitive ageing and dementia [6], with detectable impairment to memory or cognitive abilities when compared to healthy controls, but not to the extent as seen in individuals suffering with mild dementia [7]. The amnestic form of MCI has been shown to be predictive of dementia [7-10], however, the conversion 
rate has been shown to vary significantly [7] and only a minority of individuals with MCI progress to dementia within clinically relevant time frames. As a result of the heterogeneity in both the aetiology and outcome of this condition, MCI is still an area of major debate, with no consensus on its classification [11]. Reliable identification of those individuals with MCI who remain stable compared to those who decline would maximise efficacy of potential treatments and preventive interventions around this transitional stage [12]. To determine the factors that contribute to this variability in not just the rates of decline in $\mathrm{MCI}$, but also in the different cognitive abilities, will help to improve the understanding of the natural progression of decline in an ageing population.

Substantial data already exist on dementia and cognitive impairment, mainly in the older population, from using a wide range of instruments, each with merits and limitations that assess different aspects or stages of cognition. Episodic memory deficits have been shown in a number of studies to be associated with the strongest and most persistent risk of cognitive decline [13,14] and are the most common and earliest complaints in MCI [15]. However deficits in other cognitive domains can also occur, some early on, including attention, executive functioning, prospective memory, semantic memory, verbal ability, visuospatial skills, attention and processing speed [16-19]. There is a need for assessments to cover a broad range of ability and domains, and have an optimal balance between sensitivity and specificity with high positive predictive value in the settings in which they will be applied.

There are no cures for dementia, but there are some advances in the development of drugs [20] that are known to improve symptoms, or temporarily slow down disease progression in early and middle stages of the disease. To exploit the potential benefits of any such treatment and to facilitate decision making for future plans, it is important to identify early indicators of decline. However, before we are able to advise guidelines and policies on health, we need to gain better insight into the ageing process in the general population and the range of functions in both domain specific and global cognition.

The primary aim of this study was to obtain data from a general population of men and women without overt cognitive impairment using a comprehensive cognitive test battery assessing a range of function including memory (retrospective and prospective), executive function, attention, calculation, registration, language, praxis, abstract thinking, processing and new learning. The secondary aim was to explore the comparability of the different tests and their use in a community setting. We focused on producing a standardised protocol for test administration and scoring, thus minimising variation, differences in interpretation and reducing subjectivity. Details of the standardisation methods are given here.

\section{Methods}

The European Prospective Investigation of Cancer (EPIC) is a 10-country collaboration studying diet and disease with half a million participants [21,22], of which EPIC-Norfolk is one of the UK centres. Detailed descriptions of recruitment and study methods at baseline have been reported elsewhere [23]. Briefly, participants were recruited at baseline through registers in thirty five general practices in Norfolk between 1993 and 1997. General practice registers approximate population based registers as virtually all the population are registered through the UK National Health Service. Participants who consented at baseline were re-invited for a health examination at subsequent phases. The data presented here is from the third health examination $(3 \mathrm{HC}$ or EPIC-Norfolk 3) conducted between 2006 and 2011 (including data from the pilot phase between 2004 and 2006) [24]. The characteristics of the participants taking part in EPIC-Norfolk 3 are given in Table 1. Attrition rates and characteristics of these returning participants have been described previously where the cohort was shown to represent a diverse population [24]. This study was approved by the Norfolk Local Research Ethics Committee (05/Q0101/191) and East Norfolk and Waveney NHS Research Governance Committee (2005EC07L). Participants gave signed informed consent at both baseline and then subsequently at the $3 \mathrm{HC}$ to cover new measures that were not present in previous health examinations.

The Cognition battery used in EPIC-Norfolk 3 (EPICCOG) comprised of a number of validated tests that have all been described previously. These included a shortened version of the Extended Mental State Exam [25] (SF-EMSE), letter cancellation task [26] as used in the Medical Research Council Cognitive Function and Ageing Study (MRC CFAS) [27], Hopkins Verbal Learning Test (HVLT) [28], Cambridge Neuropsychological Test Automated Battery Paired Associates Learning Test (CANTAB-PAL) [29-31], Visual Sensitivity Test (VST) to assess visual impairment deficits contributing to cognitive impairment [32] Short National Adult Reading Test (Short-NART) [33] and a test for prospective memory (also as described in MRC CFAS) [34]. These tests are briefly described here with further information given in the Additional file 1 . The tests were selected with the intention to cover an array of cognitive domains and a range of difficulty. Modifications were made to shorten some of the tests to allow for use in an epidemiological setting. The battery was part of a broader health examination that lasted approximately 2-3 hours depending on the participant.

\section{Cognitive tests}

Short Form Extended Mental State Exam (SF-EMSE)

The Extended Mental State Exam (EMSE) [25] extends the widely used Mini Mental State Exam (MMSE) [35], a test known for its limitations [36,37], in particular in 
Table 1 Characteristics of the men and women in the EPIC-Norfolk 3 cohort

\begin{tabular}{|c|c|c|}
\hline Characteristic & $\begin{array}{c}\text { Men } \\
(\mathrm{N}=3861)\end{array}$ & $\begin{array}{c}\text { Women } \\
(\mathrm{N}=4762)\end{array}$ \\
\hline \multicolumn{3}{|l|}{ Mean (SD) } \\
\hline Age & $69.4(8.1)$ & $68.1(8.0)$ \\
\hline $\begin{array}{l}\text { Mental activity score } \\
\text { (from Questionnaire) }\end{array}$ & $21.1(4.7)$ & $23.2(4.7)$ \\
\hline \multicolumn{3}{|l|}{ Frequency\% (N) } \\
\hline \multicolumn{3}{|l|}{ Education level } \\
\hline Left school with no formal qualification & $22.2(857)$ & $29.7(1412)$ \\
\hline $\begin{array}{l}\text { Left school with at least O level or } \\
\text { equivalent }\end{array}$ & $77.8(3003)$ & $70.3(3349)$ \\
\hline \multicolumn{3}{|l|}{ Social class } \\
\hline I-III Non-manual & $64.5(2472)$ & $67.2(3165)$ \\
\hline III Manual-V & $35.5(1362)$ & $32.8(1544)$ \\
\hline \multicolumn{3}{|l|}{ Smoking status } \\
\hline Current & $4.2(159)$ & $4.5(213)$ \\
\hline Former & $57.8(2198)$ & $36.4(1711)$ \\
\hline Never & $38.0(1446)$ & $59.1(2774)$ \\
\hline \multicolumn{3}{|l|}{ Physical activity } \\
\hline Inactive & $37.4(1422)$ & $37.2(1748)$ \\
\hline Moderately-inactive & $25.1(954)$ & $32.2(1513)$ \\
\hline Moderately-active & $18.7(713)$ & $16.9(796)$ \\
\hline Active & $18.8(714)$ & $13.6(641)$ \\
\hline \multicolumn{3}{|l|}{ Employment and social activity } \\
\hline Retired from main occupation & $75.9(2855)$ & $78.8(3562)$ \\
\hline Active in social groups & $59.5(2264)$ & $68.5(3219)$ \\
\hline
\end{tabular}

$\mathrm{SD}=$ Standard Deviation, Frequency $\mathrm{N}=$ Number.

higher functioning individuals [25]. The original EMSE consists of 47 items in total including items from the Cambridge Mental Disorders of the Elderly Examination (CAMDEX) interview schedule [38] as well as items recommended in the report from the MRC Alzheimer's Disease Workshop in 1987 [39]. Here, we used a modified shorter version consisting of 26 selected items assessing functioning at the higher end of the ability range.

\section{Short Form Mini Mental State Exam (SF-MMSE)}

The SF-MMSE predicts the full-scale MMSE score by assuming an almost perfect performance on the excluded items in a highly functioning population [40]. The 'full derived' MMSE score (SF-MMSE Score +14) was used in the analysis here to allow the comparison of the other components of the battery using the SF-MMSE scores as a validated and recognised standard.

\section{Attention and visual search (Letter Cancellation)}

This task involved a visual search of a set of random letters with the aim of crossing out as many of the 72 possible target letters ( $\mathrm{P}$ and $\mathrm{W}$ ) within one minute. The outcome measure was 'Accuracy Score' (number of correctly identified target letters minus all potential target letters missed).

\section{Hopkins Verbal Learning Test (HVLT)}

Participants were asked to memorise words presented on a computer screen. At the end of the presentation participants were asked to recall the words. The list was shown a further two times. Correctly recalled words were recorded and the combined score of all three trials (Total HVLT Score) was used as the outcome measure.

\section{Cambridge Neuropsychological Test Automated Battery Paired Associates Learning Test (CANTAB-PAL)}

The Paired Associates Learning Test (CANTAB-PAL), tests episodic memory and new learning and has shown to be a sensitive tool as a determinant of memory deficit in the early stages of dementia [30,31,41,42]. Six white boxes (and then eight at the final stage) were presented on a touch screen, opening sequentially to display $1,2,3,6$ and then 8 abstract visual patterns. Immediately after the final test pattern was displayed, one of the patterns was displayed in the middle of the screen and the participant was required to touch the box where that pattern was located on the screen. The task consisted of eight stages and up to ten presentations after which the task terminated. The outcome measure used here was the 'first trial memory score' (FTMS), the number of patterns correctly associated to their locations in the first attempt summed across the stages completed.

\section{Visual sensitivity test (reaction time)}

This test consisted of two parts: Firstly, a triangle appeared randomly on the screen and the participant was required to press the space bar on the computer as soon as the triangle was seen. In the second part, a triangle formed from a screen full of moving dots and again the participant had to press the space bar as soon as the triangle was seen. The outcome measure of reaction time (in milliseconds) was recorded and stored automatically under the participant's unique study number.

\section{The National Adult Reading Test (NART)}

The National Adult Reading Test (NART) [43] shown to correlate with pre-morbid intelligence and general cognitive ability $[44,45]$, is accepted in both clinical and research settings. It is known to have some limitations, particularly in the less educated [46]. The participant was required to correctly pronounce the list of NART words presented on a computer screen. In this study, the short NART protocol $[33,47]$ was used. The outcome measure was 'NART Error Score', where a higher score indicates lower performance. 


\section{Prospective memory}

This is a test for the memory for future intentions, previously suggested to be sensitive to early stages of cognitive decline $[34,48]$. Participants were asked to remember to carry out an explicit instruction at a specified point later in the appointment. Participants were defined as being 'successful' if they carried out at least one correct action without having to be prompted.

\section{Covariates}

Data on covariates were obtained from a selfadministered questionnaire. Smoking status, mental activities, employment status and hobbies were obtained from responses from the health questionnaire completed near the time of EPIC-Norfolk 3. The mental activity score was calculated by assigning 1 point for an individual who reported doing a particular activity once a year or less up to 5 points if they did the activity every day. In total there were seven activities (listening to the radio, reading the newspaper, reading magazines, reading books, playing games such as cards or chess, crosswords and puzzles). The minimum score possible was 7 and the maximum was 35. Those with missing data were excluded from the analysis.

Education level was obtained from baseline questionnaire and was coded into two categories: The first consisted of those leaving school with no formal qualification (less than $\mathrm{O}$ level or equivalent). The second category consisted of those leaving school with at least some qualification. The qualification group combined those attaining O-level or equivalent (completing school to the age of 15), A-level or equivalent (completing schooling to the age of 17 years) and those obtaining a degree or equivalent.

\section{Missing data and extreme outliers}

If a test was abandoned or the participant refused to continue, the participant was scored on what had been completed and the data included in the analysis. Reasons for refusal were recorded to differentiate those participants who refused or failed to complete as a result of a technical fault or ran out of time, from those who refused because they expressed anxiety or difficulty with the task. Those who refused prior to starting a test or those who said no to a test component were assigned as missing data. Any participant identification number that could not be accurately assigned to a known individual was also removed from the final analysis as were any implausible values described below.

\section{Statistics}

The outcome measures of six of the test components were continuous. The prospective memory variable measure was dichotomised into 'successful' and 'unsuccessful'. The descriptive data (using the original untransformed scores of the continuous variables) are presented as medians and inter-quartile ranges as the cognitive scores in EPIC-COG were not normally distributed (although means and standard deviations are also presented in the Additional files 2 and 3: Table S1-S2). For the SF-EMSE Items, letter cancellation (Accuracy Score), HVLT, and CANTAB-PAL (FTMS), a higher score indicated better performance. The outcome measure for VST (reaction time) and for the NART (Short NART-Error Score), a higher score indicated poorer performance. Cross sectional data are presented by age and sex and by age, sex and MMSE Category. To give further details of the data, a graphical representation of the scores using a range of percentiles (1st, 10th, 25th, 50th, 75th, 90th and 99th) by age group and sex are also provided. Statistical analysis was performed using SPSS version 21.0 (IBM Corp., Armonk, NY, USA).

\section{Results}

Of the 8623 participants attending EPIC-Norfolk 3, 45\% $(\mathrm{n}=3861)$ were men and 55\% $(\mathrm{n}=4762)$ were women. Cognitive data were collected on 8585 individuals, with over $90 \%$ completing or attempting six or all seven of the tests in the battery. The CANTAB-PAL and VST had slightly lower completion rate (at $86.5 \%$ and $83 \%$ respectively), partly due to a technical computer failure, resulting in loss of data on 150 participants. Table 2 summarises the cognitive domains covered by each of the tests used in this study and the number of participants completing each test component.

Men and women were equally likely to complete all seven components, with 6011 (69.7\%) participants attempting all seven test components of EPIC-COG and only 850 participants (less than $10 \%$ ) of those taking part attempting or completing five components or fewer. Those completing all seven components were slightly younger (mean age 68.8 compared to 70.9 years in men and 67.4 compared to 69.8 years in women), and were more likely to be either in paid employment or actively taking part in regular social networks when compared those who did not complete all the tests. More men had left school with qualifications than women $(77.8 \%$ compared to $70.3 \%)$, although more women participated in regular social activities $(68.5 \%$ for women compared to $59.5 \%$ for men). Women also reported more mental stimulating activities in their leisure time (with mean mental activity score of 23.2 in women as compared to 21.1 for men).

Distributions for cognitive function (by each test component and stratified by sex) are presented in Figure 1. The EMSE distribution had a negative skew but did not have the same strong ceiling effect as the SF-MMSE scores in this cohort (distribution not shown), with 2298 (27\%) of participants scoring the maximum SF- MMSE score of 29 as compared to only $2.4 \%(n=200)$ scoring 
Table 2 Summary of test components of the EPIC-COG battery and the number of participants who successfully attempting all or part of each component

\begin{tabular}{|c|c|c|c|}
\hline Cognitive test & Cognitive domain & $\begin{array}{c}\text { Outcome measure* } \\
\text { (Maximum possible test score) }\end{array}$ & $\begin{array}{l}\text { Number of participants } \\
\text { attempted/completed } \\
\text { test component }\end{array}$ \\
\hline $\begin{array}{l}\text { Short form-extended mental } \\
\text { state exam (SF-EMSE) }\end{array}$ & $\begin{array}{l}\text { Global measure of cognition from MMSE to asses } \\
\text { domains for retrospective memory (immediate and } \\
\text { delayed), attention and calculation, registration, verbal } \\
\text { registration, language (object naming/sentence), } \\
\text { visual and constructional skills, praxis. Added items for } \\
\text { Memory (extension on retrospective memory), praxis, } \\
\text { verbal fluency (animal naming), language (writing to } \\
\text { dictation) and abstract thinking. }\end{array}$ & SF-EMSE Score (37) & $98 \%(8483)$ \\
\hline Letter cancellation task & $\begin{array}{l}\text { Executive function - (covering visual search, attention, } \\
\text { mental and processing speed) }\end{array}$ & $\begin{array}{l}\text { Accurately identified target letters } \\
\text { in one minute (72) }\end{array}$ & $97.5 \%(8410)$ \\
\hline $\begin{array}{l}\text { Hopkins verbal learning } \\
\text { test (HVLT) }\end{array}$ & Recognition/learning and episodic memory & $\begin{array}{l}\text { Total HVLT Score - Total of } \\
\text { correctly identified target } \\
\text { words over } 3 \text { trials (36) }\end{array}$ & $93.7 \%(8081)$ \\
\hline $\begin{array}{l}\text { CANTAB }^{\oplus} \text {-paired associate } \\
\text { learning (CANTAB-PAL) }\end{array}$ & Episodic memory and new learning/Visuospatial & First Trial Memory Score (26) & $86.5 \%(7281)$ \\
\hline Visual sensitivity test (VST) & Visuospatial (magnocellular pathway) & Reaction Time in milliseconds & $83 \%(7144)$ \\
\hline $\begin{array}{l}\text { National adult reading } \\
\text { test (NART) }\end{array}$ & Proxy Measure of IQ - Pre-morbid Intelligence & $\begin{array}{l}\text { Short NART Error Score - Using the } \\
\text { short-NART algorithm (50) }\end{array}$ & $94.1 \%(8112)$ \\
\hline Time and event based task & Prospective memory & Success vs Failure & $97 \%(8403)$ \\
\hline
\end{tabular}

*Frequencies for only one outcome measure given in this summary table.

the maximum EMSE score of 37. The data for letter cancellation (PW Accuracy) and HVLT Total Score were both approximately normal distributed, as was the distribution for FTMS (other than a peak at score 0 , which suggests that a high proportion of participants were unable to achieve a correct response immediately). The data for reaction time of the VST were highly positively skewed (as a result of a few extreme, but genuine slow responders).

For the short NART, there was a peak at the error score of 24, followed by alternating peaks and troughs in data giving a 'comb' distribution. This pattern in the distribution is as a result of the short NART algorithm (as described in the Additional file 1). The peaks in the distribution can be attributed to those assigned an error score by the algorithm, artificially inflating the scores at these points. The greatest peak (and the starting point of this comb effect of the data) was seen to occur at the cut-off point of score of 20 (giving a full NART error of $24)$, which was the point where participants with this score or lower, did not continue with the second half of the test.

The median scores of each of the test components were plotted with age in men and women as shown in Figure $2 \mathrm{a}-2 \mathrm{~g}$. The data presented here are crosssectional values showing the association of scores with age group. The graphical presentations in Figure 2 indicate that median scores decline with age. The proportion of participants successfully completing the prospective memory task lowers with increased age group. In the case of the VST (Figure 2f), the median reaction time increases with age group. The NART error score showed an increase with age initially, remains steady then a slight reduction in the oldest group (Figure 2g). In almost all tests, women generally performed better than men.

The data were further characterised by calculating percentile scores plotted by age group (Figure 3). In this figure, lower scores are seen across increasing age group. Higher percentiles of cognitive scores remain reasonably stable across age groups, but the spread and variation in scores becoming greater across each age group, with the lowest percentile having markedly lower performance. The variation in scores was least for the SFEMSE compared to the other tests in the battery. For reaction time and short NART error score, the 99th percentile indicated the poorest performers. The short NART error score exhibited widest variation across age and even some improvement in scores in the oldest age groups.

\section{Comparability of test components with the widely accepted MMSE}

The measures from each test component were compared to the MMSE, which is widely used in both research and clinical settings. The accepted cut off score of less than or equal to 23 as indicating presence of cognitive impairment has evolved from research findings [37] although higher cut-offs have been used $[49,50]$. In this high functioning cohort, there were very few individuals with a score of $\leq 23$; therefore the cut 


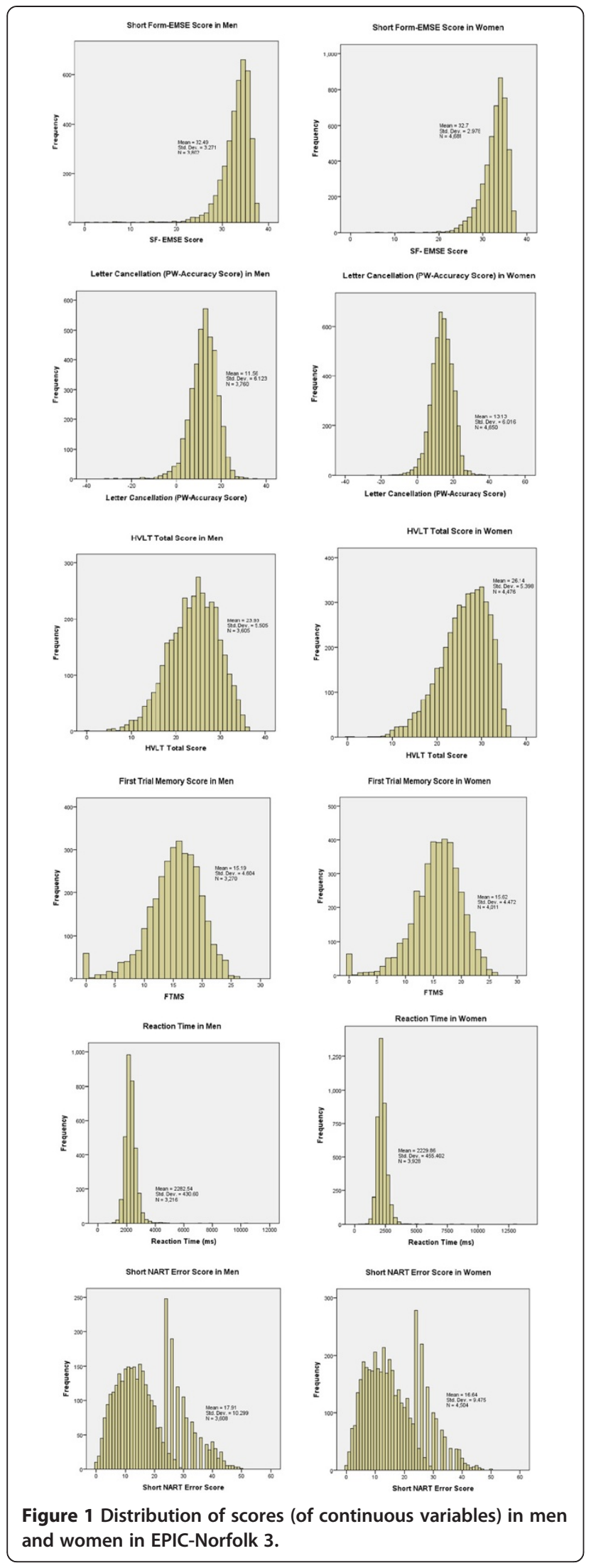

off used here for poorest performance was based on the 10 th percentile score of 24 . We used our modified form of the MMSE (i.e. SF-MMSE) and created three categories based on the distribution of SF-MMSE scores in the study population. The first category was defined as $\leq 24$ ), the third category was defined at the highest SF-MMSE scores (28 and 29) and the middle category was created using the remaining scores of 25-27.

Tables 3 and 4 shows the distribution of all the tests in EPIC-COG across the three SF-MMSE categories in men and women respectively. The general trends for all the test components were similar with the scores of the continuous test variables improving across SF-MMSE categories. For the prospective memory test, the proportion of participants successfully completing the task also increased across the three SF-MMSE categories. Again, scores in women were slightly higher than men. There was still a range of performance seen across all three SFMMSE categories.

The top performing 2298 participants who performed perfectly on the SF-MMSE (achieving a maximum possible score of 29), also included participants who were amongst the poor performers (with scores in the bottom 10th percentile) for the other components. These findings were still valid for the top $25 \%$ and for the top $10 \%$ of the SF-EMSE performers (Table 5), although the numbers were increasingly lower than those seen with the top SF-MMSE scores.

Spearman's rank correlation coefficients were calculated (Table 6) to investigate the strength of relationship between each of the tests used in EPIC-COG. The correlations were moderate to weak for most tests with HVLT having stronger associations with the other tests, such as with SF-EMSE $(r=0.49)$ followed by FTMS $(\mathrm{r}=0.38)$ and short NART $(\mathrm{r}=-0.38)$. This inverse association was as a result of the NART Error scale, with larger number representing poor performance.

To illustrate the relationship of the tests further, the distribution of the scores were plotted as contour plots (Figure 4). The contours represent the strength of the relationship between the scores of the test components. The first plot in each row shows the outcome measure variable of each individual test plotted against itself depicting the perfect positively linear association. The peak (white area) representing the region with greatest density of scores, centres at different points for each test pair combination. There seemed to be some undefined spread for each test, however there was a systematic pattern seen in all the plots, with some of the test pairs showing a better relationship than others. The general direction of the plot and the peak of overlap of scores seem to appear in areas where one would expect, however with most of the plots what is seen at best is a moderate relationship between these tests. 

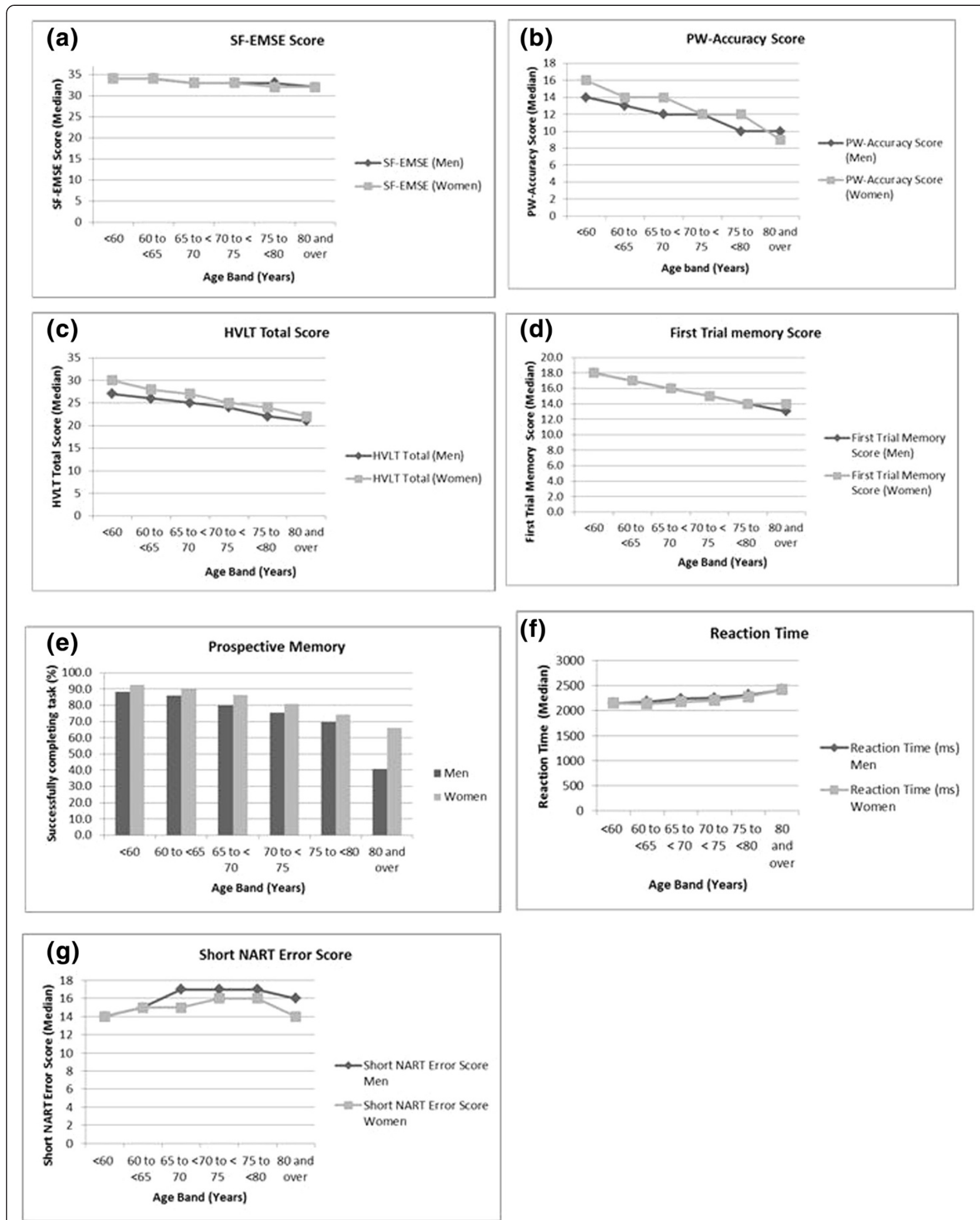

Figure $\mathbf{2}$ Cognition performance with age in men and women. $\mathbf{2 a - 2} \mathbf{d}$ are cognition test scores where higher scores indicating better performance and figures $\mathbf{2} \mathbf{f}$ and $\mathbf{2} \mathbf{g}$ are error scores where higher scores indicating poorer performance. Median values shown for the continuous variables and for prospective memory (figures $\mathbf{2 e}$ ) shown as percentage of the participants successfully completing task. 

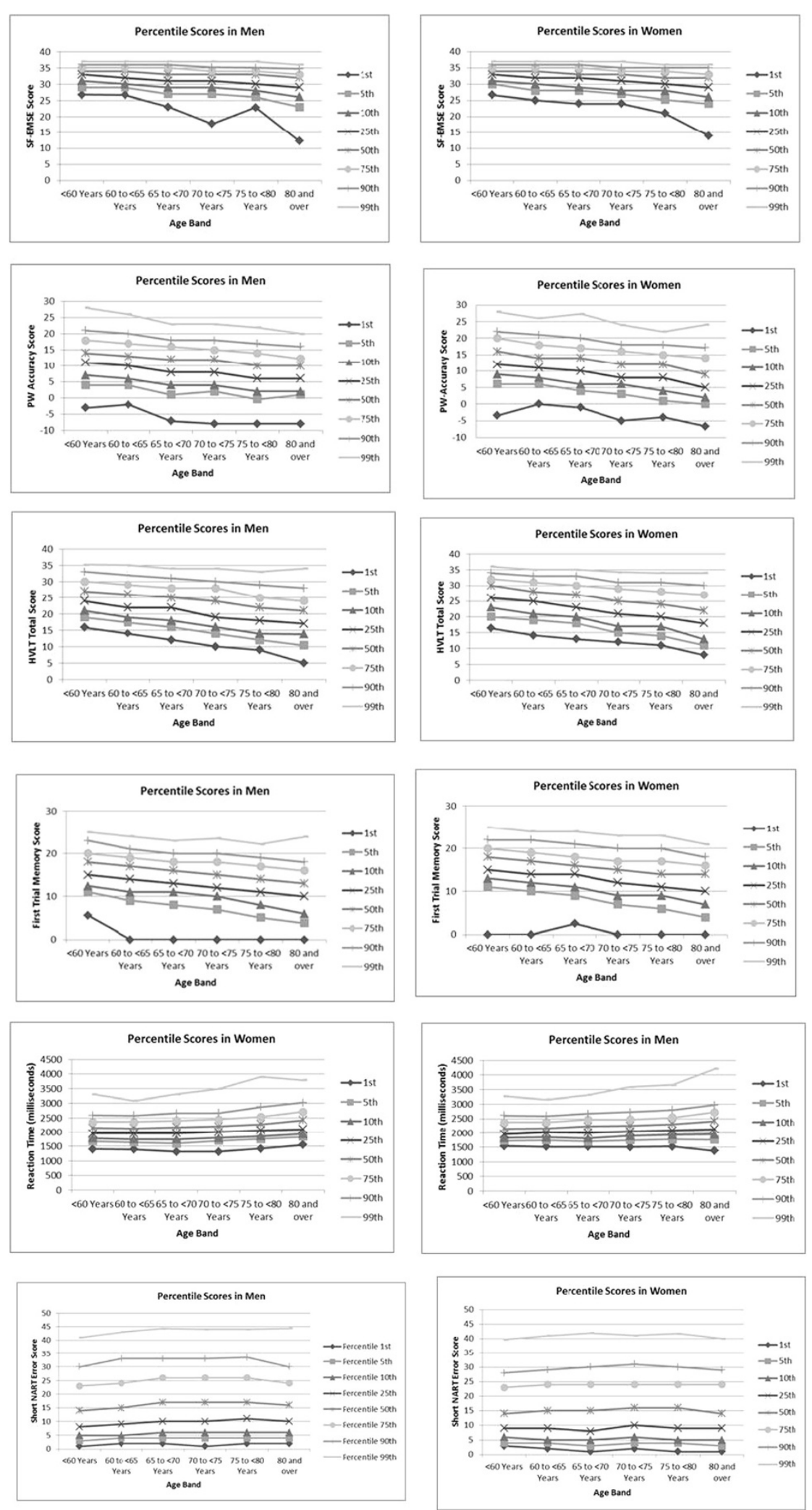

Figure 3 Cross sectional percentile levels of scores by age group in EPIC-Norfolk men and women. A graphical presentation of percentile scores plotted against age group (cross-sectional) showing performance from the highest to the lowest percentile scores in the six components of the EPIC-COG battery with continuous scores. 


\section{Discussion}

In this cross-sectional study, we report on cognitive function profiles across a range of domains using previously validated instruments in a general population of men and women from mid to later life (age 48-92 years). We focused mainly on age related differences in cognition measures, and found that, despite the EPICCOG being a relatively long battery, it was well tolerated by this general study population.

Individuals can have impairment in one cognitive domain but perform well in another or a number of cognitive deficits can occur concurrently. There is increasing evidence of substantial variability in cognitive abilities within individuals. Hilborn et al., (2009) termed this variability in performance across different tasks within an individual as 'dispersion'. It is important to gain a better understanding of the dispersion displayed by healthy individuals in order to allow accurate clinical judgment on unhealthy or abnormal dispersion [51].

Previous studies have shown that a variety of cognitive deficits are associated with preclinical stages of different types of dementias and that decline can occur in a number of cognitive domains, even before any of the clinical criteria of early stages of cognitive decline are met [52-54]. Our findings are consistent with previous studies that have shown variability and dispersion across different cognitive domains $[51,55]$ in older people. Further investigation is necessary to confirm whether the differences observed across the domains provide any meaningful indicators of cognitive performance over time.

The frequency distribution and data from the pilot (where the full NART was used for 300 participants) indicate that the short NART equation does not hold so well in this heterogeneous ageing population as it did in the homogenous sample of elderly women living in a rural setting that it was initially tested on. The aim of the short- NART was to lessen participant load and anxiety, however in an assessment such as the one in this study; participants were as likely to be anxious for any of the other components. The pilot data show that participants who obtained a score of $20(\mathrm{n}=82)$ for the first half of NART obtained a mean score of $7.9(\mathrm{SD}=3.7)$ for the second half, which is better than what the algorithm predicts. Therefore, we would recommend that despite the appeal of the short NART, this protocol is not appropriate for a higher functioning population where few individuals have poor reading skills. If there are concerns about causing distress, then we would suggest lowering the cut-off to at least 17 rather than having the cut-off at 20 .

Prevalence of severe cognitive impairment is relatively low in our cohort but as with previous studies [56,57], we also found age to be inversely associated with the complete range of cognitive function being tested with the exception of NART, where there did not seem to be any strong association between the short NART score and age. This confirms previous findings that NART is a good measure of pre-morbidity $[44,45]$ and that age has little or no effect on NART performance in the absence of early dementia [58].

We observed some differences in abilities across gender and age categories. These may have arisen because of age and sex differences in education status. Although we have not investigated education in detail here, there is good heterogeneity of individuals leaving school with and without qualifications in all age groups analysed. We also observed a trend not noted in other studies, of women performing better than men in all the test components across all age groups, even though more men than women reported leaving school with some qualification suggesting that educational status would not explain the sex differences seen in this cohort. However, women reported to be more socially active and to be doing more mentally stimulating activities in their spare time, which have been linked to better cognitive performance at older age. The effects of education, social networks and mental activity will be the focus of further research.

Although the test scores generally decline across age groups with the widest variation seen in the oldest age group, there is still a range of capability from poor to high performance in each age band, with some participants from the oldest age group outperforming their younger counterparts. Percentile scores from our crosssectional data (Figure 3) show that the greatest decline in all test components is seen in poor performers across all the age groups. This graphical presentation can be used to compare scores or estimate age and sex adjusted scores across the different domains investigated here. Individuals scoring below the 25th percentile could be considered as cognitively impaired for that domain and require further investigation.

The MMSE's lack of ability to assess individual domains and its poor sensitivity to mild cognitive impairments are frequently cited limitations $[59,60]$ This is because most healthy individuals can successfully answer most of the test items. Even though more demanding tests are available $[25,36,60,61]$, the MMSE still remains the most widely used and cited test of global cognition. To allow comparability with other studies, we included the SF-MMSE to provide a baseline for future studies and as a means of comparing the psychometric qualities and utility of the other tests used in the battery. The MMSE, being a global measure of cognition contains items that test the same domains of memory function as the other components of EPIC-COG. As expected, a positive trend was seen in all the tests with increased SF-MMSE score category, however, a range of scores 
Table 3 Distribution of cognition test component scores by MMSE cut off- score in men

\begin{tabular}{|c|c|c|c|c|c|c|c|c|c|c|c|c|}
\hline \multirow[t]{2}{*}{ Test } & \multicolumn{4}{|c|}{ MMSE score $\leq 24$} & \multicolumn{4}{|c|}{ MSSE score $25-27$} & \multicolumn{4}{|c|}{ MMSE score $28-29$} \\
\hline & $\begin{array}{l}\text { Frequency } \\
\text { (n) }\end{array}$ & Mean (SD) & Median (IQR) & Range & $\begin{array}{l}\text { Frequency } \\
\text { (n) }\end{array}$ & Mean (SD) & Median (IQR) & Range & $\begin{array}{l}\text { Frequency } \\
\text { (n) }\end{array}$ & Median (SD) & Median (IQR) & Range \\
\hline SF-ESME & 240 & $25.2(5.4)$ & $27(24,28)$ & 0,32 & 1489 & $31.3(2.2)$ & $32(30,32)$ & 17,35 & 2073 & $34.2(1.6)$ & $34(33,35)$ & 26,37 \\
\hline P-W accuracy score & 222 & $6.5(7.9)$ & $8(3,12)$ & $-28,20$ & 1474 & $10.5(5.9)$ & $11(7,14)$ & $-23,31$ & 2064 & $12.8(5.6)$ & $13(10,17)$ & $-31,34$ \\
\hline HVLT & 209 & $19.1(5.9)$ & $19(15,23)$ & 0,33 & 1391 & $22.4(5.3)$ & $23(19,26)$ & 5,35 & 1980 & $25.5(4.9)$ & $26(22,29)$ & 7,36 \\
\hline FTMS & 195 & $11.9(4.9)$ & $13(9,15)$ & 0,23 & 1258 & $14.3(4.6)$ & $15(12,18)$ & 0,26 & 1794 & $16.2(4.2)$ & $17(14,19)$ & 0,26 \\
\hline VST (ms) & 190 & 237 (733) & $2263(2063,2509)$ & 1239,10489 & 1222 & $2310(427)$ & $2260(2056,2506)$ & 567,7148 & 1777 & $2253(382)$ & $2214(2025,2442)$ & 1232,7838 \\
\hline NART error score & 200 & $25.2(11.1)$ & $26(17,33)$ & 2,50 & 1394 & $20.1(10.4)$ & $19(12,26)$ & 0,49 & 1985 & $15.6(9.4)$ & $14(8,22)$ & 0,49 \\
\hline $\begin{array}{l}\text { Prospective memory } \\
\text { (\% at least one } \\
\text { action correct) }\end{array}$ & 217 & $55 \%$ & & & 1470 & $73 \%$ & & & 2063 & $84 \%$ & & \\
\hline
\end{tabular}


Table 4 Distribution of cognition test component scores by MMSE cut off- score in women

\begin{tabular}{|c|c|c|c|c|c|c|c|c|c|c|c|c|}
\hline \multirow[t]{2}{*}{ Test } & \multicolumn{4}{|c|}{ MMSE score $\leq 24$} & \multicolumn{4}{|c|}{ MSSE score $25-27$} & \multicolumn{4}{|c|}{ MMSE score $28-29$} \\
\hline & $\begin{array}{l}\text { Frequency } \\
\text { (n) }\end{array}$ & Mean (SD) & Median (IQR) & Range & $\begin{array}{l}\text { Frequency } \\
\text { (n) }\end{array}$ & Mean (SD) & Median (IQR) & Range & $\begin{array}{l}\text { Frequency } \\
\text { (n) }\end{array}$ & Median (SD) & Median (IQR) & Range \\
\hline SF-ESME & 390 & 26.8 (3.8) & $28(26.29)$ & 4,32 & 1718 & $31.5(2.0)$ & $32(30,33)$ & 20,35 & 2573 & $34.4(1.5)$ & $35(34,35)$ & 24,37 \\
\hline P-W accuracy score & 375 & $9.3(6.4)$ & $10(613)$ & $-16,35$ & 1710 & $12.3(5.8)$ & $12(9,16)$ & $-28,32$ & 2565 & $14.3(5.8)$ & $14(11,18)$ & $-26,54$ \\
\hline HVLT & 352 & $21.1(6.0)$ & $22(17,25)$ & 5,36 & 1612 & $24.6(5.3)$ & $25(21,29)$ & 0,36 & 2467 & $27.9(4.5)$ & $29(25,31)$ & 10,36 \\
\hline FTMS & 325 & $13.2(4.5)$ & $13(11,17)$ & 0,24 & 1433 & $14.8(4.6)$ & $15(12,18)$ & 0,26 & 2212 & $16.6(4.1)$ & $17(14,19)$ & 0,26 \\
\hline VST (ms) & 302 & $2393(825)$ & $2294(2076,2538)$ & 459,12869 & 1408 & $2259(447)$ & $2216(2004,2466)$ & 1054,7973 & 2167 & $2184(374)$ & $2156(1965,2374)$ & 710,8695 \\
\hline NART error score & 358 & $24.3(10.4)$ & $24(16,31)$ & 2,50 & 1616 & $18.6(9.4)$ & $18(11,26)$ & 0,47 & 2487 & $14.3(8.4)$ & $13(8,20)$ & 0,45 \\
\hline $\begin{array}{l}\text { Prospective memory } \\
\text { (\% at least one } \\
\text { action correct) }\end{array}$ & 379 & $64 \%$ & & & 1707 & $79 \%$ & & & 2567 & $90 \%$ & & \\
\hline
\end{tabular}


Table 5 Distribution of scores in participants with near perfect SF-MMSE and SF-EMSE scores

\begin{tabular}{|c|c|c|c|c|c|c|c|c|c|c|c|c|}
\hline & \multicolumn{4}{|c|}{ (A) Top MMSE score of 29} & \multicolumn{4}{|c|}{ (B) Top $25 \%$ EMSE score ( $\geq 35$ ) } & \multicolumn{4}{|c|}{ (C) Top 10\% EMSE score $(\geq 36)$} \\
\hline & \multicolumn{2}{|r|}{ Men } & \multicolumn{2}{|c|}{ Women } & \multirow[b]{2}{*}{$\mathbf{N}^{*}$} & \multirow{2}{*}{$\begin{array}{c}\text { Men } \\
\text { Frequency } \\
\%(\mathrm{~N})\end{array}$} & \multicolumn{2}{|c|}{ Women } & \multirow[b]{2}{*}{$\mathbf{N}^{*}$} & \multirow{2}{*}{$\begin{array}{c}\text { Men } \\
\text { Frequency } \\
\%(\mathrm{~N})\end{array}$} & \multicolumn{2}{|r|}{ Women } \\
\hline & $\mathrm{N}^{*}$ & $\begin{array}{l}\text { Frequency } \\
\quad \%(N)\end{array}$ & $\mathrm{N}^{*}$ & $\begin{array}{l}\text { Frequency } \\
\quad \%(N)\end{array}$ & & & $\mathrm{N}^{*}$ & $\begin{array}{l}\text { Frequency } \\
\quad \%(\mathrm{~N})\end{array}$ & & & $\mathrm{N}^{*}$ & $\begin{array}{c}\text { Frequency } \\
\%(\mathrm{~N})\end{array}$ \\
\hline $\begin{array}{l}\text { P-W accuracy score } \\
(10 \text { th percentile }<=5)\end{array}$ & 1006 & $8.2(82)$ & 1286 & $5.3(68)$ & 1034 & $5.5(57)$ & 1336 & $4.2(56)$ & 418 & $2.9(12)$ & 569 & $3.1(18)$ \\
\hline HVLT (10th percentile <=18) & 962 & $6.7(64)$ & 1238 & $2.4(30)$ & 998 & $4.6(46)$ & 1285 & $1.1(14)$ & 404 & $1.5(6)$ & 568 & $0.5(3)$ \\
\hline FTMS (10th percentile < = 10) & 870 & $6.2(54)$ & 1122 & $4.2(47)$ & 895 & $5.1(46)$ & 1149 & $3.6(41)$ & 360 & $5.3(19)$ & 514 & $2.5(13)$ \\
\hline VST (10th percentile > =2702 ms) & 874 & $7.8(68)$ & 1100 & $5.4(59)$ & 904 & $7.1(64)$ & 1131 & $4.6(52)$ & 366 & $5.2(19)$ & 509 & $4.5(23)$ \\
\hline $\begin{array}{l}\text { Short NART error score } \\
\text { (10th percentile }>=31 \text { ) }\end{array}$ & 964 & $5.9(57)$ & 1252 & $2.6(33)$ & 1006 & $4.0(40)$ & 1308 & $1.7(22)$ & 409 & $1.7(7)$ & 577 & $1.2(7)$ \\
\hline
\end{tabular}

Participants achieving (A) Perfect MMSE Score of 29 (B) Top 25\% SF-EMSE score and (C) Top 10\% SF-EMSE score and scoring in the bottom 10th percentile of the other cognition tests.

$\mathrm{N}^{*}$ : Total Number of Participants with both test scores available.

$\mathrm{N}$ : Number of participants in the bottom 10th percentile.

were seen for other tests in each of the SF-MMSE categories.

On further investigation of participants obtaining the maximum score of 29 on the SF-MMSE, we found in the range of $6-8 \%$ of men and $2-5 \%$ of women also scored in the bottom 10th percentile of the other tests (Table 5). On examining those individuals who obtained the top $25 \%$ and further in the top 10\% SF-EMSE scores, there were still participants in poorest performers (10th percentile) of the other tests, although the figures were reduced. Those scoring in the bottom 10th percentile tended to be older than those with scores above the 10th percentile for all the tests apart from the Short NART The number of participants scoring the maximum possible on the SF-EMSE was small $(n=200)$. None of these individuals scored in the bottom 10th percentile of the other tests other than one person who scored in the lowest 10th percentile for the NART. We show that obtaining a perfect score on the MMSE does not indicate absence of impairment and this confirms previous findings for the need to supplement the MMSE in cognitive testing [37], particularly in a normal to high functioning population.

The limited reliability and validity of the MMSE in a general population has been attributed to the restricted range of MMSE. The EMSE has been shown to be sensitive across a range of performance, to avoid the ceiling effect and that (even in its short form as it has been used here), the EMSE provides extended coverage of cognitive domains (extending on attention, memory, processing and executive function). This report confirms previous findings that the EMSE has advantages over the MMSE particularly for testing individuals at the high end of the performance range [25].

Spearman's rank correlation (Table 6) show correlations are moderate to weak for most tests with HVLT having the strongest associations with other test components especially with FTMS and NART. This is not surprising, as HVLT, FTMS and NART assess similar cognitive sub domains of memory and language, however the moderate degree of correlation is somewhat counterintuitive as we would expect this to be higher. The contour plots (Figure 4) depict the spread of scores (and area of overlap) indicating that with some association, there is also some non-systematic scatter of scores suggesting that these tests may be assessing different aspects of cognitive function.

We have also addressed some practical and methodological issues with regards to minimising variability and subjectivity that can be introduced at any part of administration, scoring or cleaning of the data. We have described methods of standardisation in an epidemiological setting to ensure accuracy and consistency. Having these

Table 6 Spearman's correlation coefficient between the test components of the EPIC-COG battery

\begin{tabular}{lccccc}
\hline & SF-EMSE & PW accuracy & HVLT & FTMS & Prospective memory \\
\hline PW-Accuracy & 0.33 & & & & \\
HVLT & 0.49 & 0.33 & & & \\
FTMS & 0.34 & 0.26 & 0.38 & & \\
Prospective memory & 0.26 & 0.19 & 0.23 & 0.21 & -0.09 \\
VST & -0.16 & -0.17 & -0.17 & -0.17 & -0.13 \\
NART & -0.38 & -0.21 & -0.34 & -0.21 & 0.06 \\
\hline
\end{tabular}




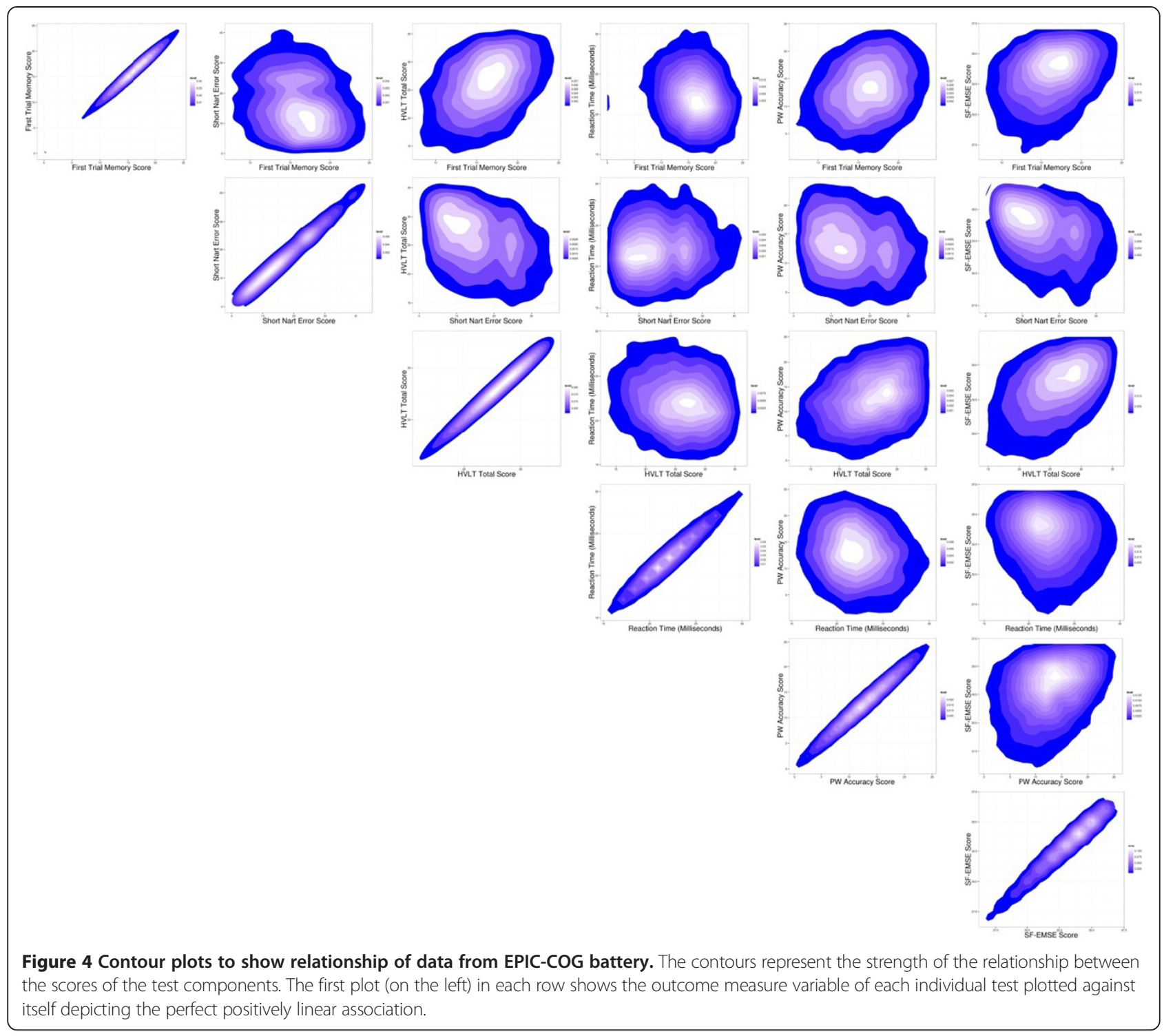

methods standardised and documented is also extremely important to allow comparability and potential harmonisation of data with other studies. The other advantage of this study over previous studies is that it has been conducted in a large well characterised cohort of men and women with good representation from a very wide age range, which has been a limiting factor in some previous studies [27,62-64].

\section{Limitations to the study}

The main limitations of this study relate to all cohort studies, and that is of healthy volunteer bias and attrition as highlighted previously [24]. However, although there is likely to be some loss of the more cognitively impaired, the oldest and frailest participants, there remains a wide range of performance and health across the whole age span of interest (from mid-life to over 90 years) represented in
EPIC-Norfolk 3. The other limitation is that this is a crosssectional study and so age differences and between persons effect can be observed but not within person differences or age related changes for which longitudinal data is required. Finally, and very importantly, we have not adjusted for the potential effects of education which is a known strong predictor of cognitive function [65-67] and on the rates of decline [68]. However, the purpose of this paper was not to look at lifestyle factors in any detail, but to present the descriptive data on this cohort. The effects of education and other factors on cognitive performance across different domains will be examined in future analysis.

\section{Conclusion}

Everyday activities in the real world are complex, requiring independence, planning, organisation, sequencing and judgement and have been shown to be a significant 
predictor of functional status [69]. Therefore, assessing cognitive function in a range of domains such as executive functions, planning, flexibility, abstract thinking, semantic memory as well as episodic memory is vital. Also of considerable importance is to accurately identify early decline in individuals or those with $\mathrm{MCI}$ who are known to be at increased risk of dementia, particularly Alzheimer's disease (AD) compared to older people without any obvious cognitive impairment.

Here we have used a comprehensive battery of accurate and well tolerated tests to provide evidence of cognitive function in a number of cognitive domains that have previously been reported to be involved in much earlier stages of decline. We have described how, even though there is reduction in performance across age, there is also a great deal of heterogeneity in older individuals. Further work is needed to understand why cognitive abilities vary so greatly across individuals and cognitive domains and to investigate the more subtle changes in cognition. We have also demonstrated that the EMSE even in its short form provides a better description of the cognitive abilities in a general functioning population and that the short NART protocol is not suitable for a heterogeneous higher functioning population. Finally, careful consideration should be given to the purpose for using a particular test (including whether the aim is to obtain global or domain specific measure, time availability and target population) when selecting an assessment tool for cognitive function.

There is epidemiological evidence of associations between lifestyle factors (such as diet, smoking and exercise) and risk of dementia [70]. The EPIC-Norfolk study has over twenty years of lifestyle, biological and genetic information, collected from mid to late in life. This study is well placed not only to identify factors associated with decline but also factors associated with maintaining abilities in older age. With the data already collected and further follow up data, we can investigate patterns of behaviours over time and predict how those behaviours affect cognitive function.

\section{Additional files}

Additional file 1: Supplementary information. Cognitive function in a general population of men and women: A cross sectional study in the European Investigation of Cancer and Nutrition-Norfolk cohort (EPIC-Norfolk).

Additional file 2: Table S1. Cognitive scores stratified by age in men in EPIC-Norfolk 3.

Additional file 3: Table S2. Cognitive scores stratified by age in women in EPIC-Norfolk 3.

\section{Competing interests}

The authors declare that they have no competing interests.

\section{Authors' contributions}

$\mathrm{SAH}$ drafted the manuscript and undertook statistical analysis with assistance and guidance from FM. ND and SM conducted and coordinated the fieldwork. The co-authors AB, SA were part of the research team involved with study design, set up and made substantial contribution to the collection of the data. $\mathrm{RL}$ assisted with data analysis and provided graphics used in the manuscript. KTK, NW and CB are principal investigators who contributed to the conception and study design and guidance on the presentation and interpretation of these data. All authors contributed to data analysis and interpretation of the data, and all authors reviewed and approved the final manuscript.

\section{Acknowledgements}

We are extremely grateful to EPIC-Norfolk participants and collaborating GP practices in Norfolk, as without their contribution this study would not be possible. We would also like to thank all staff in Norfolk and Cambridge for their dedication and hard work. We are very grateful to Cambridge Cognition (Cambridge, UK) for the free use of the CANTAB-PAL software. Unfortunately, due to rules of commercial intellectual property and confidentiality, we were unable to obtain the algorithm to gain a full understanding of the outcome measures for this test. However we are indebted to Dr Andrew Blackwell for his guidance and assistance. We thank Linda Barnes (MRC CFAS) for her assistance with training staff and data cleaning and Marleen Lentjes, Yue Leng and Victoria Keevil (University of Cambridge) for their invaluable assistance and support with the writing of this manuscript. The infrastructure for this study was supported by the Medical Research Council, UK (G0401527) and Cancer Research UK (CRUK, C864/A8257). The clinic for EPIC-Norfolk 3 was funded by Research into Ageing (262). The pilot phase was supported by MRC (G9502233) and CRUK (C864/A2883).

\section{Author details}

${ }^{1}$ Department of Public Health and Primary Care, Institute of Public Health, University of Cambridge School of Clinical Medicine, Cambridge, UK. ${ }^{2} \mathrm{MRC}$ Biostatistics Unit, Institute of Public Health, Cambridge, UK. ${ }^{3} \mathrm{MRC}$ Epidemiology Unit, University of Cambridge School of Clinical Medicine, Cambridge Biomedical Campus, Cambridge CB2 OQQ, UK.

Received: 13 August 2014 Accepted: 11 December 2014 Published: 19 December 2014

\section{References}

1. Rapp PR, Amaral DG: Individual differences in the cognitive and neurobiological consequences of normal aging. TINS 1992, 15(9):340-345.

2. Grady $\mathrm{CL}$, Craik Fl: Changes in memory processing with age. Curr Opin Neurobiol 2000, 10:224-231.

3. O'Connor DW: Memory complaints and impairment in 55 normal depressed and demented elderly persons identified in a community survey. Arch Gen Psychiatry 1990, 47:224-227.

4. Wilson RS, Beckett LA, Barnes LL, Schneider JA, Bach J, Evans DA, Bennet DA: Individual differences in rates of change in cognitive abilities of older persons. Psychol Aging 2002, 17(2):179-193.

5. Berkman LF, Seeman TE, Albert M, Blazer D, Kahn R, Mohs R, Finch C, Schneider E, Cotman C, McClearn G, Nesselroade, Featherman D, Garmezy N, McKhann G, Brim G, Prager D, Rowe J: High, usual and impaired functioning in community-dwelling older men and women: findings from the MacArthur Foundation Research Network on Successful Aging. J Clin Epidemiol 1993, 46(10):1129-1406.

6. De Jager CA, Hogervorst E, Combrinck M, Budge MM: Sensitivity and specificity of neuropsychological tests for mild cognitive impairment, vascular cognitive impairment and Alzheimer's disease. Psychol Med 2003, 33:1039-1050.

7. Peterson RC, Smith GE, Waring SC, Ivnik RJ, Tangalos EG, Kokmen E: Mild Cognitive Impairment. Clinical Characterizationand Outcome. Arch Neurol 1999, 56:303-309.

8. Bennett DA, Wilson RS, Schneider JA, Evans DA, Beckett LA, Aggarawal NT Barnes LL, Fox JH, Bach J: Natural history of mild cognitive impairment in older persons. Neurology 2002, 59:198-205.

9. Tuokko H, Frerichs R, Graham J, Rockwood K, Kristjansson B, Fisk J, Bergman H, Kozma A, McDowell I: Five-year follow-up of Cognitive Impairment with No Dementia. Arch Neurol 2003, 60:577-582. 
10. Bennet DA, Wilson RS, Schneider JA, Evans DA, Beckett LA, Aggarwal NT, Barnes LL, Fox JH, Bach J: Natural history of mild cognitive impairment in older persons. Neurology 2002, 59:198-295.

11. Stephan SBC, Matthews FE, McKeith I, Bond J, Brayne C, the MRC Cognitive Function and Ageing Study (MRC CFAS): Early cognitive change in the general population: How do different definitions work? J Am Geriatr Soc 2007, 55:1534-1549.

12. Nestor PJ, Scheltens P, Hodges JR: Advances in the early detection of Alzheimer's disease. Nat Rev Neurosci 2004, 5:S34-S41. doi:10.1038/nml1433.

13. Aggarwal NT, Wilson RS, Beck TL, Bienias JL, Bennett DA: Mild cognitive impairment in different functional domains and incident Alzheimer's disease. J Neurol Neurosurg Psychiatry 2005, 76:1479-1484. doi:10.1136 jnnp.2004.053561.

14. De Jager CA, Schrijnemaekers ACMC, Honey TEM, Budge MM: Detection of $\mathrm{MCl}$ in the clinic: evaluation of the sensitivity and specificity of a computerised test battery, the Hopkins Verbal Learning Test and the MMSE. Age Ageing 2009, 38(4):455-460. doi:10.1093/ageing/afp068.

15. Petersen RC, Doody R, Kurz A, Mohs RC, Morris JC, Rabins PV, Ritchie K, Rossor M, Thal L, Winblad B: Current Concepts in Mild Cognitive Impairment. Arch Neurol 2001, 58:1985-1992.

16. Tucker-Drob EM: Global and domain-specific changes in cognition throughout adulthood. Dev Psychol 2011, 47(2):331-343.

17. Ylikoski R, Ylikoski A, Keskivaara P, Tilvis R, Sulkava R, Erkinjuntti T: Heterogeneity of cognitive profiles in aging: successful aging, normal aging, and individuals at risk for cognitive decline. Eur J Neurol 1999, 6(6):645-652.

18. Perry RJ, Watson P, Hodges JR: The nature and staging of attention dysfunction in early (minimal and mild) Alzheimer's disease: relationship to episodic and semantic memory impairment. Neuropsychologia 2000 38:252-271.

19. Bäckman L, Jones S, Berger AK, Laukka EJ, Small BJ: Multiple cognitive deficits during the transition to Alzheimer's disease. J Intern Med 2004 256:195-204.

20. Overshott R, Burns A: Treatment of dementia. J Neurol Neurosurg Psychiatry 2005, 76:v53-v59. doi:10.1136/jnnp.2005.082537.

21. Riboli E, Kaaks R: The EPIC Project: rationale and study design. European Prospective Investigation into Cancer and Nutrition. Int J Epidemiol 1997, 26(Suppl 1):S6-S14.

22. Riboli E: Background and rationale of the European Prospective Investigation into Cancer and Nutrition (EPIC). Ann Oncol 1992, 3:783-791.

23. Day N, Oakes S, Luben R, Khaw KT, Bingham S, Wareham N: Study design and characteristics of the cohort. EPIC-Norfolk: European Prospective Investigation of Cancer. Br J Cancer 1999, 80(Suppl 1):95-103.

24. Hayat SA, Luben R, Keevil VL, Moore S, Dalzell N, Bhaniani A, Khawaja AP Foster P, Brayne C, Wareham NJ, Khaw KT: Cohort Profile: A prospective cohort study of objective physical and cognitive capability and visual health in an ageing population of men and women in Norfolk (EPIC-Norfolk 3). Int J Epidemio/ 2013:1-10. doi:10.1093/ije/dyt086.

25. Huppert FA, Cabelli ST, Matthews FE, the MRC Cognitive Function and Ageing Study (MRC CFAS): Brief cognitive assessment in a UK population sample - distributional properties and the relationship between the MMSE and an extended mental state examination. BMC Geriatr 2005, 5:7. doi:10.1186/1471-2318-5-7.

26. Richards $M$, Kuh D, Hardy R, Wadsworth M: Lifetime cognitive function and timing of the natural menopause. Neurology 1999, 53(2):308-314.

27. MRC CFAS: Cognitive function and dementia in six areas of England and Wales: The distribution of MMSE and GMS organicity level in the MRC CFA Study. The Medical Research Council Cognitive Function and Ageing Study (MRC CFAS). Psychol Med 1998, 28:319-335.

28. Brandt J: The Hopkins Verbal Learning Test: Development of a new memory test with six equivalent forms. Clin Neuropsychol 1991, 5:125-142.

29. Sahakian B, Morris R, Evenden J, Heald A, Levy R, Philpot M, Robbins T: A comparative study of visuospatial memory and learning in Alzheimertype dementia and Parkinson's disease. Brain 1988, 111:695-718.

30. Fowler KS, Saling MM, Conway EL, Semple JM, Louis WJ: Paired Associates Performance in the early detection of DAT. J Int Neuropsychol Soc 2002, 8(1):58-71.

31. Fowler KS, Saling MM, Conway EL, Semple JM, Louis WJ: Computerized neuropsychological tests in the early detection of dementia. J Int Neuropsychol Soc 2002, 3:139-146

32. Kirby $E$, Bandelow S, Hogervorst E: Visual impairment in Alzheimer's Disease. J Alzheimers Dis 2010, 21:15-34.
33. Beardsall $L$, Brayne $C$ : Estimation of verbal intelligence in an elderly community: A prediction analysis using a shortened NART. Br J Clin Psychol 1990, 29:83-90.

34. Huppert FA, Johnson AL, Nickson J, MRC CFAS: High prevalence of Prospective Memory Impairment in the Elderly and in Early-stage Dementia: Findings from a Population-based Study. Appl Cognit Psychol 2000, 14:S63-S81.

35. Folstein MF, Folstein SE, McHugh PR: "Mini-mental state". A practical method for the cognitive state of patients for the clinician. J Psychiatr Res 1975, 12:189-198.

36. Teng EL, Chui HC: The Modified Mini-Mental State (3MS) examination. J Clin Psychiatry 1987, 48:314-318.

37. Tombaugh TN, Mclntyre NJ: The mini-mental state examination: a comprehensive review. J Am Geriatr Soc 1992, 40:922-935.

38. Roth M, Tym E, Mountjoy CQ, Huppert FA, Hendrie H, Verma S, Goddard R: CAMDEX. A standardised instrument for the diagnosis of mental disorder in the elderly with special reference to the early detection of dementia. Br J Psychiatry 1986, 149:698-709.

39. Medical Research Council: Report form the MRC Alzheimer's Disease Workshop. Medical Research Council; 1987

40. Matthews FE, Stephan BCM, Khaw KT, Hayat S, Luben R, Bhaniani A Moore S, Brayne C: Full-scale scores of the Mini Mental State Examination can be generated from an abbreviated version. $J$ Clin Epidemiol 2011, 64(9):1005-1013.

41. Swainson R, Hodges JR, Galton CJ, Semple J, Michael A, Dunn BD, Iddon JL, Robbins TW, Sahakian BJ: Early detection and differential diagnosis of Alzheimer's disease and depression with neuropsychological tasks. Dement Geriatr Cogn Disord 2001, 12:265-280.

42. Blackwell AD, Sahakian BJ, Vesey R, Semple J, Robbins TW, Hodges JR: Detecting Dementia. Novel neuropsychological markers of pre-clinical Alzheimer's Disease. Dement Geriatr Cogn Disord 2004, 17:42-48.

43. Nelson HR: National Adult Reading Test (NART): Test Manual. Windsor: NFER-Nelson; 1982

44. Crawford JR, Parker DM, Stewart LE, Besson JA, De Lacy G: Prediction of WAIS IQ with the National Adult Reading Test. Br J Clin Psychol 1989, 28:267-273.

45. Crawford JR, Deary IJ, Starr J, Whalley LJ: The NART as an index of prior intellectual functioning: a retrospective validity study covering a 66-year interval. Psychol Med 2001, 31:451-458.

46. Brayne C, Beardsall L: Estimation of verbal intelligence in an elderly community: An epidemiological study using NART. Br J Clin Psychol 1990 29:21-223.

47. Crawford JR, Parker DM, Allan KM, Jack AM, Morrison FM: The Short NART: Cross-validation, relationship to $\mathrm{IQ}$ and some practical considerations. Br J Clin Psychol 1991, 30:223-229.

48. Huppert FA, Beardsall L: Prospective memory impairment as an early indicator of dementia. J Clin Exp Neuropsychol 1993, 15:805-821.

49. Ismail Z, Rajji TK, Shulman Kl: Brief cognitive screening instruments: An Update. Int J Geriatr Psychiatry 2010, 25(2):111-120.

50. Lacy M, Kaemmerer T, Czipri S: Standardized Mini-Mental State Examination Scores and Verbal Memory Performance at a Memory Center: Implications for Cognitive Screening. Am J Alzheimers Dis Other Demen 2014, 1-8 doi:10.1177/1533317514539378

51. Hilborn JV, Strauss E, Hultsch DF, Hunter MA: Intra-individual variability across cognitive domains: Investigation of dispersion levels and performance profiles in older adults. J Clin Exp Neuropsychol 2009, 31(4):412-424

52. Cullum S, Huppert FA McGee M, Dening T, Ahmed A, Paykel ES, Brayne C: Decline Across Different Domains of Cognitive Function in Normal Ageing. Results of a Longitudinal Population Based Study using CAMCOG. Int J Geriatr Psychiatr 2000, 15(9):853-862.

53. Colie A, Maruff $P$, Shafiq-Antonacci $R$, Smith M, Hallup M, Schofield PR, Masters $\mathrm{CL}$, Currie J: Memory decline in healthy older people. Implications for identifying mild cognitive impairment. Neurology 2001, 56:1533-1538.

54. Weaver Cargin J, Maruff P, Collie A, Masters C: Mild memory impairment in healthy older adults is distinct from normal aging. Brain Cogn 2006, 60:146-155.

55. Christensen $H$, Mackinnon AJ, Korten AE, Jorm AF, Henderson AS, Jacomb $P$ Rodgers B: An Analysis of Diversity in the Cognitive Performance of Elderly Community Dwellers: Individual Differences in Change Scores as a Function of Age. Psychol Aging 1999, 14(3):365-379. 
56. White L, Katzman R, Losonczy K, Salive M, Wallace R, Berkman L, Taylor J, Fillenbaum G, Havlik R: Association of Education with incidence of Cognitive Impairment in Three Established Populations for Epidemiological Studies of the Elderly. J Clin Epidemiol 1994, 47:363-374.

57. Brayne C, Gill C, Paykel ES, Huppert F, O'Connor DW: Cognitive Decline in an Elderly Population - A Two Wave Study of Change. Psychol Med 1995, 25:673-683.

58. Crawford JR, Stewart LE, Garthwaite PE, Parker DM, Besson JAO: The relationship between demographic variables and NART performance in normal subjects. Br J Clin Psychol 1988, 27:181-182.

59. Beatty WW, Goodkin DE: Screening for cognitive impairment in multiple sclerosis. An evaluation of the Mini-Mental State Examination. Arch Neurol 1990, 47:297-301.

60. Tombaugh TN, McDowell I, Krisjansson B, Hubley AM: Mini-Mental State Examination (MMSE) and the Modified MMSE (3MS): A psychometric comparison and normative data. Psychol Assess 1996, 8:48-59.

61. Nasreddine ZS, Phillips NA, Bédirian V, Charbonneau S, Whitehead V, Collin I, Cummings JL, Chertkow H: The Montreal Cognitive Assessment, MoCA: a brief screening tool for mild cognitive impairment. J Am Geriatr SoC 2005, 53:695-699.

62. Fleming J, Zhao E, O'Connor DW, Pollitt PA, Brayne C, the CC75C study: Cohort Profile: The Cambridge City over-75s Cohort (CC75C). Int J Epidemiol 2007, 36:40-46. doi:10.1093/ije/dyl293.

63. Caerphilly and Speedwell Collaborative group: Caerphilly and Speedwell collaborative heart disease studies. J Epidemiol Community Health 1984, 38:259-262.

64. Christensen H, Jorm AF, Henderson AS, Mackinnon AJ, Korten AE, Scott LR: Therelationship between health and cognitive functioning in an elderly community sample. Age Ageing 1994, 23:204-212.

65. Jagger C, Matthews R, Melzer D, Matthews F, Brayne C, MRC CFAS: Educational differences in the dynamics of disability incidence, recovery and mortality: Findings from the MRC Cognitive Function and Ageing Study (MRC CFAS). Int J Epidemiol 2007, 36:358-365. doi:10.1093/ije/dyl307.

66. O'Connor DW, Pollitt PA, Treasure FP, Brook CPB, Reiss BB: The influence of education, social class and sex on Mini-Mental State scores. Psychol Med 1989, 19:771-776.

67. Brayne C, Calloway P: The association of education and socioeconomic status with the Mini Mental State Examination and the clinical diagnosis of dementia in elderly people. Age Ageing 1990, 19:91-96.

68. Scarmeas N, Albert SM, Manly JJ, Stern Y: Education and rates of cognitive decline in incident Alzheimer's disease. J Neurol Neurosurg Psychiatry 2006, 77:308-316. doi:10.1136/jnnp.2005.072306.

69. Bell-McGinty S, Podell K, Franzen M, Baird A, Williams M: Standard measure of executive function in predicting instrumental activities of daily living in older adults. Int I of Geriatr Psychiatry 2002, 17:828-834.

70. Barnett JH, Hachinski V, Blackwell AD: BMC Med 2013, 11:246. doi:10.1186/ 1741-7015-11-246.

doi:10.1186/1471-2318-14-142

Cite this article as: Hayat et al:: Cognitive function in a general population of men and women: a cross sectional study in the European Investigation of Cancer-Norfolk cohort (EPIC-Norfolk). BMC Geriatrics 2014 14:142.

\section{Submit your next manuscript to BioMed Central and take full advantage of:}

- Convenient online submission

- Thorough peer review

- No space constraints or color figure charges

- Immediate publication on acceptance

- Inclusion in PubMed, CAS, Scopus and Google Scholar

- Research which is freely available for redistribution 